\title{
Análise da tradução/ adaptação de textos dramáticos sob a perspectiva da Linguística de Corpus
}

\author{
Ana J ulia Perrotti-Garcia*
}

\begin{abstract}
Computer tools may help the analysis of written texts. The aim of the present study was to determine if such tools would also be useful for the analysis of drama texts. The following computer tools were used in the present study: a worl-list generator, an aligner and a parallel concordancer. The tapescript of the English dramatist David Farrs' play Ruckus in the Garden, and its Brazilian Portuguese translated version were part of the study corpus. The pilot study has shoen that the computer tools can help systematize and treat linguistic data to be analysed, speeding analysis and making it more consistent.
\end{abstract}

Keywords: Translation - Corpus linguistics - Drama texts.

Resumo: As ferramentas computadorizadas podem ajudar na análise de textos em geral. 0 objetivo do presente estudo foi testar se tais ferramentas também poderiam ser úteis ao analisar textos dramáticos. As ferramentas computacionais incluídas no presente estudo são: um gerador de listas de palavras, um alinhador e um concordanciador paralelo. Para a análise, utilizamos a peça Ruckus in the Garden, escrita por David Farr, dramaturgo britânico e sua tradução ao português. A partir da pesquisa aqui realizada, pudemos concluir que as ferramentas computacionais ajudam na sistematização e no tratamento dos dados a serem analisados, tornando mais ágil e consistente a manipulação dos textos a serem pesquisados.

Palavras-chave: Tradução - Linguístca de corpus - Textos dramáticos.

Doutoranda no DLM FFLCH USP. Tradutora e professora universitária. Email: drajulia@gmail.com. 
Perrotti-Garcia, Ana J ulia - Análise da tradução/ adaptação de textos dramáticos sob a perspectiva da Linguística de Corpus

\section{Introdução}

As ferramentas computadorizadas podem ajudar na análise de textos em geral. Os softwares para análise textual permitem que o usuário estude padrões linguísticos, determine a frequência de ocorrência de palavras ou frases em certos textos e analise palavras em contexto. A autora do presente estudo propõe o estabelecimento de uma metodologia computadorizada de tratamento dos dados para a análise de adaptações/traduções de textos dramáticos. Essa metodologia consiste do uso de ferramentas computacionais que ajudam a sistematizar a análise comparativa de um texto dramático e / ou de suas traduções/adaptações, ou a análise comparativa de duas ou mais traduções/ adaptações entre si.

Tradução e Linguística de Corpus são duas áreas que já estão bastante aproximadas - há trabalhos bastante relavantes na área, que unem ambas as ciências, com a finalidade de pesquisa ou para o desenvolvimento de novas ferramenats de trabalho. Mona Baker fez um levantamento bastante abrangente dos Estudos de Tradução com base em corpus (BAKER 1995) que foi posteriormente complementado pelo trabalho de Sara LAVIOSA (2002). Na década que se sucedeu, muitos outros trabalhos relevantes foram publicados, tanto em livros, quanto em dissertações e teses.

No cenário brasileiro, em um levantamento realizado nas bases de dados da Biblioteca Digital de Teses e Dissertações da Universidade de São Paulo, por considerarmos que esta instituição possa refletir uma parcela significativa da produção científica brasileira. A partir desse levantamento, obtivemos três teses e quatro dissertações, totalizando sete estudos (Fromm 2008; GineZI 2008; TeixeIRA 2008; Fonseca 2007; Lamparelli 2007; Martins 2007; GONÇALVES 2006).

As ferramentas computacionais incluídas no presente estudo são: um gerador de listas de palavras, um alinhador e um concordanciador paralelo. 
Perrotti-Garcia, Ana J ulia - Análise da tradução/ adaptação de textos dramáticos sob a perspectiva da Linguística de Corpus

0 gerador de listas de palavras utilizado (WordList, do programa WordSmith versão 3) cria listas de palavras (ou grupos de palavras), classificando-as em ordem alfabética e de frequência de ocorrência (BERBER SARDINHA 1999). O estudo da frequência de ocorrência de certas palavras pode ser muito útil para que o pesquisador que analisa um texto possa ter uma compreensão mais aprofundada das escolhas lexicais ou fraseológicas de um determinado autor ou de certo tradutor/adaptador, por exemplo.

Se 0 tradutor/pesquisador pretende estudar um texto original e sua tradução, o alinhador de textos paralelos pode ser usado para relacionar segmentos do texto de partida com a respectiva tradução do texto de chegada, sucessivamente.

Depois de alinhados, os textos podem ser analisados com o auxílio de um concordanciador paralelo, tanto por uma abordagem diacrônica (se, por exemplo, utilizarmos duas traduções de uma certa obra, feitas em pontos cronológicos distintos), diatópica (duas traduções adaptadas para públicos geograficamente distintos, ou escritas em variantes linguísticas diferentes, por exemplo), ou para públicos-alvo de diferentes faixas etárias, níveis sociais, graus de instrução ou objetivos da obra dramática (comédia, tragédia etc.). o concordanciador paralelo permite que o pesquisador localize, rapidamente e com reprodutibilidade, todos os segmentos (frases ou parágrafos) em que se encontra(m) determinada(s) palavra(s) de busca. Os resultados são mostrados juntamente com os respectivos segmentos da língua de partida.

Para teste da exequibilidade do uso de tais ferramentas computadorizadas na análise de traduções/adaptações de textos dramáticos (PARTINGTON 2008), esta pesquisa procurou determinar as limitações, vantagens e desvantagens de tais ferramentas.

Como embasamento teórico/metodológico, temos a Linguística de Corpus (LC), que é a área da Linguística Aplicada que se ocupa da coleta e análise de dados linguísticos coletados criteriosamente (ditos corpora, palavra 
Perrotti-Garcia, Ana J ulia - Análise da tradução/ adaptação de textos dramáticos sob a perspectiva da Linguística de Corpus

latina plural de corpus) (Berber Sardinha 2004). Para a LC, os textos que vão constituir um corpus de estudo precisam ser coletados segundo critérios préestabelecidos, devem estar em formato que possa ser processado em programas de computador (em geral, com a extensão .txt, ou seja, texto sem formatação) e, acima de tudo, precisam ser textos autênticos (não inventados). Assim, escolhemos uma peça real, que foi escrita originalmente para ser encenada em inglês (Ruckus in the Garden, de David Farr), e que posteriormente foi traduzida para o público brasileiro (recebendo o título de Treta no J ardim, adaptação de Mário Viana). Além da comparação de ambas as listas de palavras (WordLists) ordenadas por frequência de ocorrência, também analisamos a ocorrência de bigramas, trigramas e quadrigramas (que são, respectivamente, conjuntos de duas, três e quatro palavras ocorrendo lado a lado). O subcorpus contendo o texto original (Ruckus in the Garden) tem 10.755 tokens (ou seja, total de palavras, també, chamado de "ocorrências") e 1.827 types (ou seja, palavras diferentes entre si). Já o arquivo contendo a tradução (Treta no Jardim) tem 11.017 tokens e 2.114 types. Além do estudo das listas de palavras, como veremos a seguir, os dois textos foram alinhados e analisados.

\section{Ferramentas computacionais empregadas nesta pesquisa}

A linguística de corpus tem se beneficiado muito dos avanços tecnológicos, e um número crescente de ferramentas computacionais, corpora e programas de tratamento de texto vai sendo disponibilizado a cada dia.

Como já foi dito anteriormente, o alinhador de textos paralelos é usado para estabelecer uma correspondência entre os segmentos do texto de partida com a respectiva tradução do texto de chegada. Entre os alinhadores disponíveis, o alinhador Vanilla Aligner é em geral citado como bastante 
Perrotti-Garcia, Ana J ulia - Análise da tradução/ adaptação de textos dramáticos sob a perspectiva da Linguística de Corpus

utilizado. Entretanto, como para se trabalhar com o texto em um software alinhador, é necessário um pré-processamento (DANIELSSON e RIDINGS 1997), muitas vezes bastante trabalhoso e distante da prática de muitos tradutores. Por essa razão, no presente estudo optamos por usar uma ferramenta que fosse mais conhecida desses profissionais. Para o alinhamento dos segmentos utilizamos a ferramenta Plus Tools, que pode ser baixada gratuitamente no site do programa Wordfast. O Plus tools é usado para a geração de memórias de tradução pelos usuários de ferramentas de auxílio à tradução (as chamadas CAT tools). 0 funcionamento do programa é o seguinte: primeiramente 0 usuário escolhe, em uma caixa de diálogo que se abre ao acionar o ícone do programa instalado na barra de ferramentas do Word, qual será o texto de partida e o texto de chegada (ou então, abre apenas os dois documentos no porgrama MS Word). A seguir, ao clicar em "Align", e o Plus tools gera uma tabela contendo na coluna da esquerda o texto de partida e à direita o de chegada. O programa segmenta os textos segundo a presença de pontos finais, dois pontos, pontos de interrogação ou de exclamação (ou seja, ".", ":", "?", "!") e marcas de parágrafo e faz um alinhamento provisório. Caberá ao pesquisador, nesta fase, conferir se para cada frase do texto de partida está alinhada a frase de chegada correspondente. Para fazer os ajustes, basta utilizar os comandos da guia Tabela do programa MS Word (por exemplo, "inserir linha", "excluir linha", "mesclar células", entre outros).

Tão logo o pesquisador considere que o alinhamento esteja correto, deve clicar no botão "Generate TM" do Plus Tools que o programa irá gerar um arquivo em formato somente texto (.txt) contendo os segmentos alinhados. Este arquivo originalmente é gerado para servir como memória de tradução do programa Wordfast, mas pode ser utilizado como um corpus paraleo alinhado, no qual podemos fazer pesquisas linguísticas.

Em geral, após o alinhamento de um texto, é utilizado um concordanceador paralelo para a pesquisa de termos e expressões. Um concordanceador paralelo bastante útil, de acesso livre e gratuito, foi 
Perrotti-Garcia, Ana J ulia - Análise da tradução/ adaptação de textos dramáticos sob a perspectiva da Linguística de Corpus

desenvolvido pelos pesqusiadores do CEPRIL (PUC-SP). Essa ferramenta deve ser precedida pelo alinhador online disponibilizado no mesno website.

Para o presente estudo, entretanto, como nossa pesquisa estava enfocando aspectos mais relacionados à adaptação de certos aspectos culturais do que de detrminadas palavras, utilizamos o corpus alinhado pelo Plus tools, em sua fase intermediária, ou seja, ainda no formato de duas colunas.

\section{Da obra analisada e sua adaptação para o português do Brasil: o Projeto Conexões}

A peça Ruckus in the Garden foi escrita por David Farr, dramaturgo britânico, especialmente para participar do Projeto Conexões, uma iniciativa do London National Theatre. A primeira edição do projeto, segundo informações do site do Projeto, contou com a participação de nove grupos de Teatro Jovem de diferentes regiões da cidade de São Paulo (Brasil), envolvendo cerca de 130 participantes. Além de peças de dois autores brasileiros (Marcelo Rubens Paiva e Caco Barcellos), os autores ingleses David Farr e J udith J ohnson tiveram suas peças traduzidas para integrar o portfólio da primeira edição. Como já foi dito anteriormente, Farr escreveu Ruckus in the Garden especialmente para esse projeto. A versão em português chamouse Treta no Jardim e foi adaptada pelo jornalista e dramaturgo Mario Viana. Tanto o texto em inglês quanto sua tradução tem como público-alvo uma plateia jovem, embora a peça possa se assistida por crianças e adultos. 


\section{Procedimentos de tradução - procedimentos de adaptação?}

Embora em geral o alinhamento de textos seja feito frase a frase, no caso em estudo, por tratar-se de uma peça teatral em que a unidade de análise nos pareceu ser cada turno de fala (line) de um determinado personagem, optamos por alinhar os dois textos (Ruckus in the Garden e Treta no J ardim) fala a fala, mesmo que uma determinada fala fosse formada por mais de uma frase.

Após o alinhamento inicial, cada segmento foi lido, analisado e quando o texto apresentasse não apenas a tradução literal do original, mas alguma modificação considerada como fruto de adaptação, as palavras envolvidas na adaptação eram realçadas em negrito e o tipo de adaptação era classificado. Desse modo, foi utilizada uma metodologia manual de tratamento dos dados, assistida por ferramentas computacionais.

A partir da análise dos excertos alinhados, e reorganizados segundo a ocorrência de procedimentos de adaptação, observamos em maior frequência os seguintes procedimentos: troca por equivalentes locais (domesticação); substituição por hiperônimo ou termo genérico, omissão e explicitação; tradução de nomes de animais e nomes próprios; aspectos culturais e geográficos.

A seguir, abordaremos em maiores detalhes os aspectos relacionados a esses procedimentos de tradução/adaptação. As gírias, palavras de baixo calão, expressões indicativas de oralidade, termos da mitologia e religiosos em geral, embora bastante presentes nos textos analisados, serão abordados em outros estudos desenvolvidos pela autora. 


\section{a. Troca por equivalentes locais (domesticação)}

\section{Com relação à troca por equivalentes locais (domesticação),} observamos na linha de concordância 1 do quadro a seguir que o termo olive branch, que nas culturas orientais simboliza boa vontade e paz, foi trocado por "cachimbo da paz", que é um termo bastante idiomático. Segundo o site Filologia.org.br, "fumar o cachimbo, o que representava um ato simbólico dos indígenas tornou-se, entre os povos civilizados, uma expressão que significa 'chegar a um acordo'." Na linha de concordância 2, a atriz estadunidense Scarlett J ohanssen foi substituída pela top model brasileira Gisele Bündchen.

\begin{tabular}{|c|c|}
\hline $\begin{array}{l}\text { 1- Stanley } \\
\text { I'm offering the olive branch. }\end{array}$ & $\begin{array}{l}\text { Lucas } \\
\text { Estou of erecendo o cachimbo da paz. }\end{array}$ \\
\hline $\begin{array}{l}\text { 2- Billie } \\
\text { So you don't have skin like Scarlett } \\
\text { J ohanssen. Your mum lives next to a } \\
\text { bypass and smokes four hundred } \\
\text { cigarettes a day. }\end{array}$ & $\begin{array}{l}\text { Bia } \\
\text { Tudo bem, você pode não ter a pele da } \\
\text { Gisele Bündchen. Sua mãe mora perto do } \\
\text { viaduto e fuma quatrocentos cigarros por } \\
\text { dia. }\end{array}$ \\
\hline $\begin{array}{l}\text { 3- Maisy } \\
\text { How could they have let us come here } \\
\text { on the same day as Riverdale! } \\
\text { Riverdale should be doing something } \\
\text { useful like visiting a remand centre } \\
\text { or going on a hip hop course. }\end{array}$ & $\begin{array}{l}\text { Gabi } \\
\text { Como eles puderam nos trazer aqui no } \\
\text { mesmo dia que o Rubinato? O pessoal do } \\
\text { "Rouba-e-Mata" deveria estar fazendo } \\
\text { alguma coisa mais útil, tipo visitando a } \\
\text { Febem ou tendo aula de hip hop. }\end{array}$ \\
\hline
\end{tabular}

Também exemplificando a domesticação do texto, o termo remand center, que se refere a uma instituição prisional para indivíduos que aguardam julgamento, foi substituído por "FEBEM", que é uma instituição brasileira, destinada a menores infratores ou não, que embora não seja mais denominada desse modo (o nome atual é Fundação CASA, segundo o site da própria instituição), ainda é bastante conhecida do público em geral. 
Perrotti-Garcia, Ana J ulia - Análise da tradução/ adaptação de textos dramáticos sob a perspectiva da Linguística de Corpus

\begin{tabular}{|l|l|}
\hline 4- Frazer & Tiago \\
That's cos they're rugby players innit. & Foi porque eles têm jogadores de vôlei \\
But we got that sorted this time. We & $\begin{array}{l}\text { que são quase profissionais. Mas desta vez } \\
\text { brought ammo. }\end{array}$ \\
\hline $\begin{array}{l}\text { 5- They all want me to take part in this } \\
\text { stupid fight. I hate it, just because I'm a }\end{array}$ & $\begin{array}{l}\text { Todos querem que eu entre nessa briga } \\
\text { idiota. Dá uma raiva. Só porque sou forte, } \\
\text { big guy and I work out and play football } \\
\text { for the county, everyone expects me to } \\
\text { faço exercícios e o sendo sondado pra } \\
\text { be sogar na linga sub-20, todos esperam que } \\
\text { eu monster... }\end{array}$ \\
\hline
\end{tabular}

$\mathrm{Na}$ linha de concordância 4, acima, rugby players foi trocado por "jogadores de vôlei" e no excerto 5, o termo football, que se refere ao futebol americano, foi substituído pela referência à "liga sub-20", de futebol de campo, um esporte muito mais popular no Brasil do que o citado no original.

\begin{tabular}{|c|c|}
\hline $\begin{array}{l}\text { 6- Cath } \\
\text { Three years ago. My dad took us to Thorpe } \\
\text { Park. I think it was by way of an early } \\
\text { apology. Three days later he ran off with } \\
\text { the hairdresser. }\end{array}$ & $\begin{array}{l}\text { Carol } \\
\text { Há três anos. Meu pai levou a gente ao } \\
\text { Parque do Carmo. Acho que foi um } \\
\text { pedido de desculpas adiantado. Três } \\
\text { dias depois ele fugiu com a } \\
\text { cabeleireira da rua de baixo. }\end{array}$ \\
\hline $\begin{array}{l}\text { 7- Fraser } \\
\text { Why didn't the }\end{array}$ & $\begin{array}{l}\text { Tiago } \\
\text { Eu prefe }\end{array}$ \\
\hline
\end{tabular}

Nas linhas de concordância 6 e 7, observamos que Thorpe Park, um parque nos arredores de Londres, foi substituído pelo Parque do Carmo (que fica na periferia de São Paulo) e Alton Towers, que é um importante parque temático inglês, foi substituído por Hopi Hari, um parque temático nas imediações de São Paulo.

\begin{tabular}{|c|c|}
\hline $\begin{array}{l}\text { 8- Frazer } \\
\text { (...) and so are they and what else are } \\
\text { we going to do? Smell the tulips? }\end{array}$ & $\begin{array}{l}\text { Tiago } \\
\text { (...) e o que (mais) a gente vai fazer aqui? } \\
\text { "Aspirar o perfume das rosas"? }\end{array}$ \\
\hline $\begin{array}{l}\text { 9- Cath } \\
\text { Well I'm lined up for Cambridge Uni } \\
\text { but I might choose London Uni } \\
\text { because I like to mix my academic } \\
\text { work with living in a thriving urban } \\
\text { scene. }\end{array}$ & $\begin{array}{l}\text { Carol } \\
\text { Bem, tô rachando pra entrar na Unicamp, } \\
\text { mas não ia ficar nada chateada se } \\
\text { entrasse na USP mesmo. Ou a PUC. Sabe, } \\
\text { eu gosto de misturar o lance acadêmico } \\
\text { com a balada urbana. }\end{array}$ \\
\hline
\end{tabular}


Perrotti-Garcia, Ana J ulia - Análise da tradução/ adaptação de textos dramáticos sob a perspectiva da Linguística de Corpus

Já na linha de concordância 8, nota-se a substituição de tulipas por rosas, que são flores certamente bem mais populares no Brasil do que as primeiras. Na linha de concordância número 9, observamos que as universidades inglesas (Cambridge e London) foram substituídas por universidades paulistas (UNICAMP e USP), ambientando a história não só no Brasil, mas mais especificamente no estado de São Paulo.

Evidentemente, outros aspectos que revelam a domesticação sofrida pelo texto serão abordados mais adiante, pois a troca por equivalentes locais não é a única estratégia de tradução que permite conseguirmos domesticar um texto traduzido.

\section{b. Substituição por hiperônimo ou termo genérico}

Quanto à substituição por termo genérico ou hiperônimo (superordenado), uma vez que a peça em português foi montada de modo a ser ambientada no Brasil (haja vista os exemplos de tradução por equivalentes, citados anteriormente), alguns elementos geográficos ou culturais foram substituídos por termos mais genéricos ou neutros, de modo a fazer um apagamento das referências Britânicas ou europeias.

No quadro a seguir, observamos que o original utilizava o termo spaniel, que se refere a uma raça específica de cachorros, mas a tradução apresenta o hiperônimo "cachorro", embora no diminutivo.

Tamsen

I love you Hugh. You can do what you want with me. Beat me, use me as your spaniel, I am not letting go!

Talita
Eu te amo, Hugo. Faça o que quiser de
mim. Me faz um cafuné, me usa como seu
cachorrinho. Não vou deixar você ir
embora.

\section{Talita}

Eu te amo, Hugo. Faça o que quiser de cachorrinho. Não vou deixar você ir embora.

No próximo excerto, observamos que o nome da casa de campo (Homesleigh) foi substituído pelo termo genérico "casa de campo", uma estratégia bastante domesticadora, já que no Brasil não temos o hábito de 
Perrotti-Garcia, Ana J ulia - Análise da tradução/ adaptação de textos dramáticos sob a perspectiva da Linguística de Corpus

chamar sítios e casas de campo pelo nome, como é bastante comum no Reino Unido, onde se passa originalmente a história da peça.

\begin{tabular}{|l|l|}
\hline Stanley (reading) & Lucas (lendo) \\
Nestling in deep wooded countryside, & Em 1920, Moses Rosenblitz desenhou os \\
Cecil Fortescue created Homesleigh in & jardins de sua casa de campo, em \\
1720 as a token of love for his French & $\begin{array}{l}\text { homenagem ao seu amor por sua esposa } \\
\text { francesa, Amélia. }\end{array}$ \\
wife Amelia. &
\end{tabular}

0 mesmo pode ser dito do exemplo abaixo, no qual Labour party foi substituído por "um partido mais a esquerda", fazendo-se o apagamento das referências ao partido britânico. Nesse mesmo trecho, mais adiante no excerto, encontramos um exemplo de explicitação (joke e "piada de mau gosto"), que será explicado mais a frente.

\begin{tabular}{|l|l|}
\hline Cath & Carol \\
He's going to talk to us about the & Ele vai dar uma palestra sobre os \\
problems of post-apartheid South & problemas da África do Sul pós-apartheid. \\
Africa. It's going to be fascinating. And & Vai ser fascinante. E depois vou fazer \\
then I'm going to go into politics. & carreira política. Num partido mais à \\
Labour party probably though I reckon & esquerda. Na minha opinião, precisamos \\
we need to take a long hard look at & dar uma boa olhada no nosso sistema \\
the whole party-political system which & político partidário, que está se \\
is rapidly becoming a joke. & transformando em uma piada de mau \\
& gosto. \\
\hline
\end{tabular}

Na linha de concordância a seguir, a palavra "estrada", embora mais genérica, acabou sendo usada também para explicitar o significado de A36. Se o termo fosse mantido como no original, poderia não ser compreendido pelos expectadores brasileiros, já que nosso sistema de denominação de estradas é baseado no uso de duas letras iniciais, BR para as rodovias federais e, para as estaduais, a sigla do estado (SP, RJ etc.) e por dois e três números (por exemplo, SP55; BR116 etc.). 
Perrotti-Garcia, Ana J ulia - Análise da tradução/ adaptação de textos dramáticos sob a perspectiva da Linguística de Corpus

\section{Frazer}

Last night I got so wasted I ended up puking in a ha ha by the $\mathbf{A} \mathbf{3 6}$.
Tiago

Ontem à noite eu enchi tanto a cara que acabei vomitando em um sulco perto da estrada.

Nas linhas de concordância apresentadas a seguir, temos dois pontos turísticos ingleses que foram trocados por referências genéricas, como 0 zoológico londrino Whipsnade que foi substituído apenas pelo termo "Jardim Zoológico" e Megabowl que foi traduzido apenas como "boliche".

\begin{tabular}{|l|l|}
\hline Rock & Geleia \\
When we fought them at & $\begin{array}{l}\text { Quando a gente saiu na porrada com eles no } \\
\text { Whipsnade zoo this big floppy } \\
\text { Jardim Zoológico, aquele cara de cabelo em } \\
\text { haired guy called Moose broke } \\
\text { Casey Martin's ankle. }\end{array}$ \\
$\begin{array}{l}\text { Frazer } \\
\text { Cássio Marting. }\end{array}$ \\
$\begin{array}{l}\text { Why were you seen weeping at the } \\
\text { Megabowl? }\end{array}$ & $\begin{array}{l}\text { Tiago } \\
\text { (Então) Por que você estava chorando no } \\
\text { boliche? }\end{array}$ \\
\hline
\end{tabular}

Nos próximos trechos apresentados, temos o apagamento da palavra Britain (Grã-Bretanha) e sua substituição pelo hiperônimo "país".

\begin{tabular}{|l|l|}
\hline Stanley & Lucas \\
You know we'll be blamed. It will be & Você sabe que a gente vai levar a culpa. \\
the same old story. The poor unwashed & Vai ser a mesma história de sempre. "A \\
sink school scum attack the future of & escória da escola de pias encardidas \\
Britain. We always come off worse! If & ataca os futuros mandatários do país". A \\
we are ever going to change our & gente sempre se dá mal. Se quisermos \\
society - we have to make the first \\
move.
\end{tabular}

\section{c. Omissão e explicitação}

Quanto à omissão e explicitação, dois procedimentos bastante comuns em tradução, quando utilizados para suprimir aspectos redundantes ou explicar tópicos que não sejam de fácil compreensão pelo leitor do texto de chegada, respectivamente, na tradução desta peça, podemos citar algumas ocorrências bastante interessantes. 
Perrotti-Garcia, Ana J ulia - Análise da tradução/ adaptação de textos dramáticos sob a perspectiva da Linguística de Corpus

As linhas de concordância a seguir ilustram algumas ocorrências desses procedimentos. Na linha (a)1, o original citava o termo in the rhododendra, que foi omitido na tradução. 0 mesmo ocorreu com o adjetivo polished, na linha (a)2, que não se encontra na tradução.

\begin{tabular}{|c|c|}
\hline (a) Omissão & \\
\hline $\begin{array}{l}\text { 1-Maisy } \\
\text { We're meant to hide in the rhododendra } \\
\text { under the statue of cupid and make an } \\
\text { owl-call if we see anything. }\end{array}$ & $\begin{array}{l}\text { Gabi } \\
\text { É para a gente se esconder debaixo das } \\
\text { estátuas de cupidos e dar um grito de } \\
\text { coruja se virmos algo. }\end{array}$ \\
\hline 2- My skin is polished marble & Minha pele é como mármore \\
\hline
\end{tabular}

O excerto (a)3 exemplifica a omissão do nome do lago (Hesperus), que foi traduzido apenas como "lago". Também podemos observar uma interferência na formatação do texto, pois a expressão You will listen, no original, foi grafada totalmente em letras maiúsculas, procurando deixar claro que a frase deveria ser falada enfaticamente, aos gritos, talvez. Entretanto, na tradução, essa informação foi omitida, e a frase "E vocês vão assistir" aparece apenas com a inicial da primeira palavra em maiúscula. A linha de concordância (a)4, abaixo, ilustra a omissão de of Hercules, que foi traduzido apenas como "estátua".

\begin{tabular}{|c|c|}
\hline $\begin{array}{l}\text { 3- You threw stones at us. You threw } \\
\text { me into the lake of Hesperus. But we } \\
\text { are still here. Now together we will } \\
\text { perform the action and YOU WILL } \\
\text { LISTEN! }\end{array}$ & $\begin{array}{l}\text { Vocês nos apedrejaram. Vocês me } \\
\text { jogaram no lago. Mas continuamos aqui. } \\
\text { Agora, juntos faremos o ritual. E vocês } \\
\text { vão assistir! }\end{array}$ \\
\hline $\begin{array}{l}\text { 4- Tamsen } \\
\text { Well it's either you or that statue of } \\
\text { Hercules. }\end{array}$ & $\begin{array}{l}\text { Talita } \\
\text { Bem ou é você ou aquel }\end{array}$ \\
\hline
\end{tabular}

Já em (b)1, o texto traduzido explica que Afrodite é a deusa do amor, uma informação que não constava no original. Mais detalhes sobre a tradução de termos da mitologia podem ser encontrados mais adiante neste texto. 
Perrotti-Garcia, Ana J ulia - Análise da tradução/ adaptação de textos dramáticos sob a perspectiva da Linguística de Corpus

\begin{tabular}{|l|l|}
\hline (b) Explicitação & \\
\hline $\begin{array}{l}\text { 1- Tamsen } \\
\text { I don't know, just to spend some time } \\
\text { together here in the temple of Aphrodite... }\end{array}$ & $\begin{array}{l}\text { Talita } \\
\text { Sei lá. Só ficar aqui no Templo de } \\
\text { Afrodite. A Deusa do Amor. }\end{array}$ \\
\hline
\end{tabular}

Conforme citado anteriormente, a linha de concordância (b)2 apresenta um exemplo de explicitação, pois o original usava a penas o termo joke, e a tradução acrescentou a locução adjetiva "de mau gosto", talvez em uma tentativa de se aproximar mais da idiomaticidade da fala brasileira, na qual o termo "piada de mau gosto" é bastante recorrente. Em (b)3, a tradução explicita o significado de Asbos (que é a sigla para o termo em inglês AntiSocial Behaviour Order), ao utilizar o termo "advertências por mau comportamento".

\begin{tabular}{|l|lr|}
\hline $\begin{array}{l}\text { 2- Labour party probably though I } \\
\text { reckon we need to take a long hard look }\end{array}$ & $\begin{array}{l}\text { Na minha opinião, precisamos dar uma } \\
\text { boa olhada no nosso sistema político } \\
\text { at the whole party-political system } \\
\text { which is rapidly becoming a joke. }\end{array}$ & $\begin{array}{l}\text { partidário, que está se transformando } \\
\text { em uma piada de mau gosto. }\end{array}$ \\
\hline $\begin{array}{l}\text { 3- Stanley } \\
\text { (...) Asbos, exclusion orders... it's doing } \\
\text { my head in. }\end{array}$ & $\begin{array}{llll}\text { Lucas } & & & \\
& \text { comportamento, Advertências por ameaças r mau } \\
\text { expulsão... Eu tô pirando. }\end{array}$ \\
\hline
\end{tabular}

\section{d. Tradução de nomes de animais e nomes próprios}

Em relação à tradução de nomes de animais e nomes próprios, embora tenhamos feito um levantamento dos nomes dos personagens, no presente estudo, abordaremos apenas o tratamento dados ao nome das escolas (St Nectans e Riverdale) e da própria peça (Ruckus in the Garden). As demais análises serão apresentadas oportunamente, em outra publicação da mesma autora.

Vejamos abaixo o tratamento dados ao nome das escolas (St Nectans e Riverdale): 
Perrotti-Garcia, Ana J ulia - Análise da tradução/ adaptação de textos dramáticos sob a perspectiva da Linguística de Corpus

\begin{tabular}{|l|l|}
\hline $\begin{array}{l}\text { Representing St Nectan's Grant } \\
\text { Maintained Secondary }\end{array}$ & Representando a Colégio Sagrado Coração \\
\hline $\begin{array}{l}\text { Representing Riverdale } \\
\text { Comprehensive }\end{array}$ & $\begin{array}{l}\text { Representando o Colégio Estadual J oão } \\
\text { Rubinato, que eles chamam de Rouba-e-Mata }\end{array}$ \\
\hline
\end{tabular}

Os nomes das escolas foram adaptados, procurando manter a coerência que havia no original, ou seja, a escola particular recebeu um nome religioso (St Nectan's tornou-se "Sagrado Coração") e a escola pública recebeu o tradicional "Colégio Estadual", acrescido de um nome próprio. Em geral, as escolas estaduais no Brasil recebem nomes de antigos professores, ou de escritores ou artistas. E esta não foi a exceção, pois o escolhido pelo adaptador foi João Rubinato, que é nome de batismo do músico paulista Adoniran Barbosa.

Os excertos acima mostram que o adaptador teve liberdade inclusive de acrescentar informações que não constavam do original. Levando em consideração o caráter humorístico da peça, e com base no costume adolescente de colocar apelidos e modificar o nome das pessoas, o texto em português já em sua apresentação das escolas acrescenta a frase "que eles chamam de Rouba-e-Mata", ao referir-se ao colégio estadual. A seguir, mais alguns excertos que exemplificam essa adaptação.

\begin{tabular}{|c|c|}
\hline $\begin{array}{l}\text { Maisy } \\
\text { How could they have let us come } \\
\text { here on the same day as Riverdale! } \\
\text { Riverdale should be doing } \\
\text { something useful like visiting a } \\
\text { remand centre or going on a hip hop } \\
\text { course. }\end{array}$ & $\begin{array}{l}\text { Gabi } \\
\text { Como eles puderam nos trazer aqui no } \\
\text { mesmo dia que o Rubinato? O pessoal do } \\
\text { "Rouba-e-Mata" deveria estar fazendo } \\
\text { alguma coisa mais útil, tipo visitando a } \\
\text { FEBEM ou tendo aula de hip hop. }\end{array}$ \\
\hline $\begin{array}{l}\text { Maisy } \\
\text { Keep your voice down. Riverdale } \\
\text { could be anywhere. }\end{array}$ & $\begin{array}{l}\text { Gabi } \\
\text { Fala baixo. Os Rouba-e-Mata podem estar } \\
\text { por perto. }\end{array}$ \\
\hline
\end{tabular}

Nas duas linhas de concordância apresentadas anteriormente, a expressão "Rouba-e-Mata" foi usada em substituição ao nome original do colégio, sendo que no segundo o termo foi usado para indicar os próprios alunos do Rubinato. 
Perrotti-Garcia, Ana J ulia - Análise da tradução/ adaptação de textos dramáticos sob a perspectiva da Linguística de Corpus

\begin{tabular}{|l|l|}
\hline Maisy & Gabi \\
I got away. Dived through a camelia & Escapei. Mergulhei entre as camélias e me \\
and crawled round the Temple of & arrastei em volta do Templo de Flora. Dois \\
Flora. Two Riverdale boys were & brucutus do Rubinato estavam \\
pinning a St Nectans ninth year up \\
against a statue of Vulcan.
\end{tabular}

No excerto acima, entre outros aspectos analisados em diferentes pontos deste estudo, salientamos o emprego do termo "brucutus" como tradução de boys, que foi claramente uma escolha que procurou salientar a imagem que os alunos do colégio particular tinham dos colegas da escola pública. 0 termo "brucutu", segundo o Dicionário Informal, é uma gíria para uma pessoa "ríspida, grosseira", sendo assim, sua inclusão reforça o caráter rústico dos alunos do colégio Rubinato, e somado ao fato de serem chamados de "Rouba-e-Mata", temos a construção de uma imagem de violência e agressividade bem mais intensa do que a apresentada no original.

Ao analisarmos as linhas de concordância produzidas pela ferramenta Concord do programa WordSmith tools (versão 3.0), como é possível observar no Quadro 1, algums aspectos importantes precisam ser salientados, principalmente ao leitor não acostumado à "leitura" desse tipo de texto. Primeiramente, notamos que existe sempre uma palavra central em negrito. Essa é a chamada "palavra de busca" ou "nódulo" da linha de concordância. Ao redor do nódulo, temos um número igual de caracteres, à direita e à esquerda.

0 fato de o programa colocar um número fixo de caracteres faz com que palavras sejam, algumas vezes, cortadas nas extremidades das linhas de concordância, causando o que a primeira vista pode parecer ser "palavras faltando" ou "letras soltas". Entretanto, à medida que o pesquisador começa a acostumar seu olhar, acaba percebendo que a análise se faz sempre a partir do nódulo, para a direita e/ ou a esquerda, dependendo do que se quer estudar. 
Perrotti-Garcia, Ana J ulia - Análise da tradução/ adaptação de textos dramáticos sob a perspectiva da Linguística de Corpus

É possível modificar a quantidade de caracteres ao redor do nódulo, expandindo o que se chama de "horizonte", ou co-texto, mas em hipótese alguma o pesquisador pode alterar as linhas, nem corrigir a ortografia ou a gramática das linhas de concordância, uma vez que elas são expressões de uma realidade linguística, ou seja, como os corpora são sempre coletados a partir de textos autênticos, refletirão a língua em sua autenticidade.

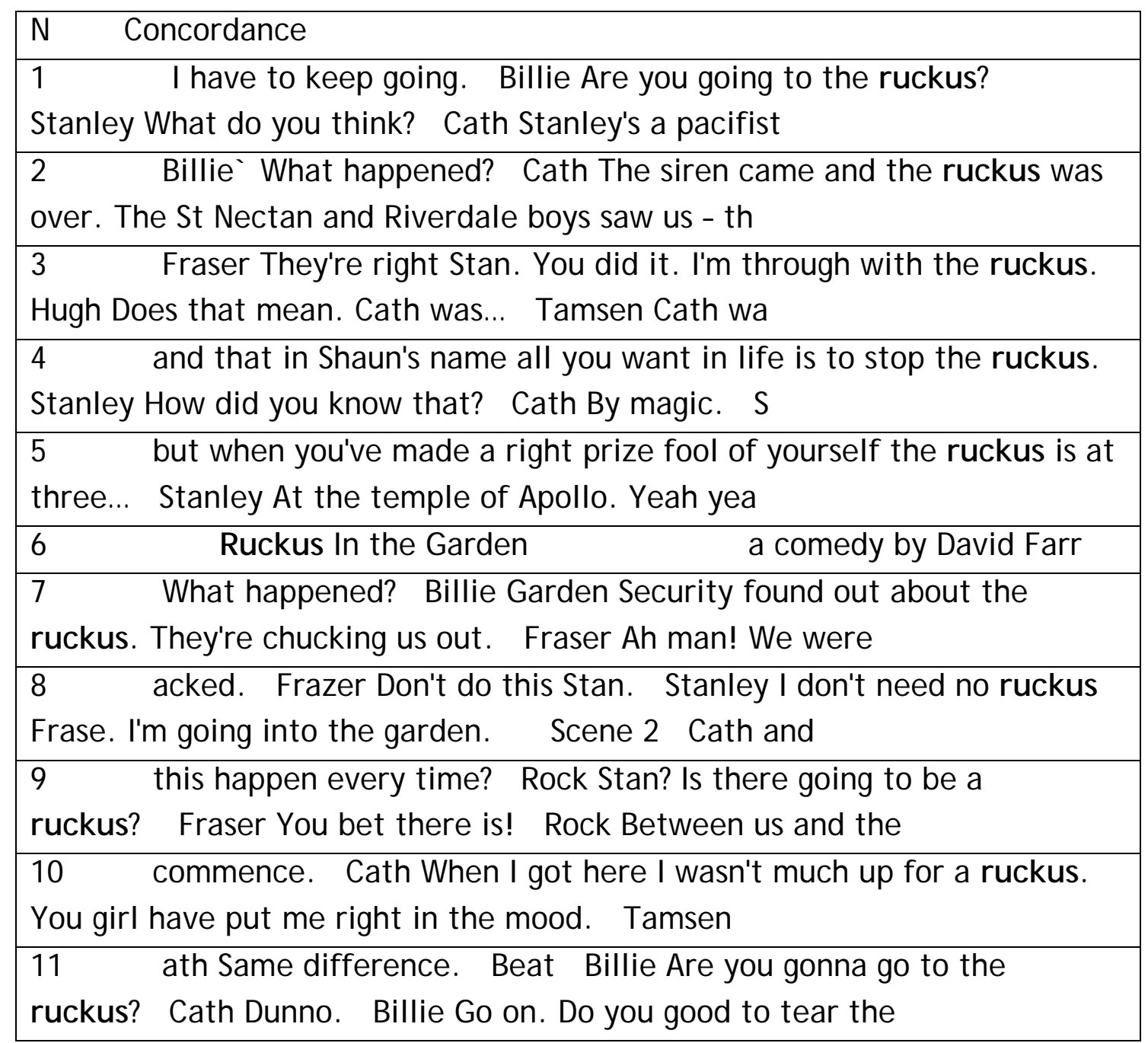

Quadro 1: Ocorrências da palavra ruckus no texto original.

Com relação ao uso da palavra ruckus, empregada no título e, como observamos no Quadro 1 (acima), utilizada mais dez vezes em outros momentos da peça, a tradução não foi feita sempre da mesma maneira. Assim 
Perrotti-Garcia, Ana J ulia - Análise da tradução/ adaptação de textos dramáticos sob a perspectiva da Linguística de Corpus

como no título (linha de concordância 1, abaixo), ruckus foi traduzido por "treta" em mais três pontos do texto (linhas de concordância 2 a 4). Em dois casos (linhas de concordância 5 e 6), ruckus foi traduzido como "briga" e em um como o verbo "brigar". Nos demais, foram utilizados os termos "luta", "combate", "pancadaria" e "quebra-pau", uma vez cada um (linhas de concordância 8 a 11).

\begin{tabular}{|c|c|}
\hline 1- Ruckus In the Garden & Treta no J ardim \\
\hline $\begin{array}{l}\text { 2- Cath } \\
\text { When I got here I wasn't much up for a } \\
\text { ruckus. You girl have put me right in } \\
\text { the mood. }\end{array}$ & $\begin{array}{l}\text { Carol } \\
\text { Quando cheguei aqui, não estava muito } \\
\text { a fim de uma treta. Você conseguiu me } \\
\text { colocar no espírito da coisa. }\end{array}$ \\
\hline $\begin{array}{l}\text { 3- Cath } \\
\text { The same reason I know that your dad's } \\
\text { a nutter who you do everything to avoid } \\
\text { and your brother Shaun died in a fight } \\
\text { outside a nightclub three years ago and } \\
\text { that in Shaun's name all you want in life } \\
\text { is to stop the ruckus. }\end{array}$ & $\begin{array}{l}\text { Carol } \\
\text { Pelo mesmo motivo que sei que seu pai } \\
\text { é um louco que você tenta evitar a todo } \\
\text { custo e que seu irmão Douglas morreu } \\
\text { em uma briga na porta de um clube há } \\
\text { três anos e que em nome dele o que } \\
\text { você mais quer na vida é acabar com as } \\
\text { tretas. }\end{array}$ \\
\hline $\begin{array}{l}\text { 4- Fraser } \\
\text { They're right Stan. You did it. I'm } \\
\text { through with the ruckus. }\end{array}$ & $\begin{array}{l}\text { Tiago } \\
\text { É verdade, Lucas. Você conseguiu! Eu } \\
\text { parei com a treta. }\end{array}$ \\
\hline $\begin{array}{l}\text { 5- Billie } \\
\text { Garden Security found out about the } \\
\text { ruckus. They're chucking us out. }\end{array}$ & $\begin{array}{l}\text { Bia } \\
\text { A Segurança do Jardim descobriu tudo } \\
\text { sobre a briga. Estão mandando a gente } \\
\text { embora. }\end{array}$ \\
\hline $\begin{array}{l}\text { 6- Cath } \\
\text { The siren came and the ruckus was } \\
\text { over. The St Nectan and Riverdale boys } \\
\text { saw us - they thought it was us that had } \\
\text { snitched on them. }\end{array}$ & $\begin{array}{l}\text { Carol } \\
\text { A sirene tocou e a briga terminou. Os } \\
\text { rapazes do Sagrado Coração e do J oão } \\
\text { Rubinato nos viram - eles acharam que } \\
\text { fomos nós que deduramos. }\end{array}$ \\
\hline $\begin{array}{l}\text { 7- Stanley } \\
\text { I don't need no ruckus Frase. I'm going } \\
\text { into the garden. }\end{array}$ & $\begin{array}{l}\text { Lucas } \\
\text { Eu não preciso brigar, Tiago. Vou entrar } \\
\text { no jardim. }\end{array}$ \\
\hline $\begin{array}{l}\text { 8-Billie } \\
\text { Are you going to the ruckus? }\end{array}$ & $\begin{array}{l}\text { Bia } \\
\text { Você vai à luta? }\end{array}$ \\
\hline $\begin{array}{l}\text { 9- Fraser } \\
\text { Ok but when you've made a right prize } \\
\text { fool of yourself the ruckus is at three... }\end{array}$ & $\begin{array}{l}\text { Tiago } \\
\text { Tudo bem, mas quando você tiver } \\
\text { acabado de bancar o idiota, o combate } \\
\text { vai ser às três, valeu? }\end{array}$ \\
\hline $\begin{array}{l}\text { 10- Rock Stan? Is there going to be a } \\
\text { ruckus? }\end{array}$ & $\begin{array}{l}\text { Geléia } \\
\text { Lucas? Vai sair pancadaria? }\end{array}$ \\
\hline $\begin{array}{l}\text { 11- Billie } \\
\text { Are you gonna go to the ruckus? }\end{array}$ & $\begin{array}{l}\text { Bia } \\
\text { Você vai participar do quebra-pau? }\end{array}$ \\
\hline
\end{tabular}


Perrotti-Garcia, Ana J ulia - Análise da tradução/ adaptação de textos dramáticos sob a perspectiva da Linguística de Corpus

\section{e. Adaptação de aspectos geográficos/ culturais}

\section{e.1 Maioridade aos 16 anos}

Como no Reino Unido a maioridade para tirar carta de motorista é aos 16 anos, e os personagens da peça estão no ensino médio, algumas adaptações precisaram ser feitas, para evitar que o texto ficasse incoerente ou apresentasse situações "impossíveis" ou "ilegais". Na linha de concordância apresentada no quadro abaixo, o personagem Frazer fala sobre os jovens ricos que dirigem carros novos. Na tradução, observamos o termo "andam de carro novo", sem deixar claro se eles estariam dirigindo ou se estariam sendo levados por outra pessoa.

\section{Frazer}

Cos they drive those new minis, and cos they have okra in their packed lunch, I dunno!

\section{Tiago}

Porque eles andam de carro novo e comem lanche orgânico! Sei lá, cara.

0 diálogo a seguir mostra claramente esse aspecto relacionado à diferença de idade para um jovem ser considerado maior. Na versão em português, inclusive, foi preciso acrescentar a palavra "nem", e yet foi deslocado para o final da frase. Assim, a tradução literal que deveria ser "Ainda não tenho 16", passa a ser "Não tenho nem dezesseis anos ainda", que é reforçada pela frase seguinte, em que 0 aniversário de 16 anos é substituído pelo de 18 - que no Brasil seria o momento em que ela poderia se casar legalmente.

\begin{tabular}{|c|c|}
\hline $\begin{array}{l}\text { Hugh } \\
\text { Hold on to him. Marry him } \\
\text { immediately }\end{array}$ & $\begin{array}{l}\text { Hugo } \\
\text { Não deixa ele escapar. Casa com ele } \\
\text { imediatamente. }\end{array}$ \\
\hline $\begin{array}{l}\text { Tamsen } \\
\text { I'm not sixteen yet. }\end{array}$ & $\begin{array}{l}\text { Talita } \\
\text { Não tenho nem dezesseis anos ainda. }\end{array}$ \\
\hline $\begin{array}{l}\text { Hugh } \\
\text { Book it for your sixteenth birthday. } \\
\text { The world is full of insane maniacs. A } \\
\text { decent human being is gold dust! }\end{array}$ & $\begin{array}{l}\text { Hugo } \\
\text { Deixa reservado para o seu aniversário de } \\
\text { dezoito anos. O mundo é cheio de gente } \\
\text { louca. Um ser humano decente é raro } \\
\text { como pó de ouro! }\end{array}$ \\
\hline
\end{tabular}


Perrotti-Garcia, Ana J ulia - Análise da tradução/ adaptação de textos dramáticos sob a perspectiva da Linguística de Corpus

\section{e. 2 Sistema de ensino}

Uma vez que a história traduzida se passa no Brasil, onde o sistema de ensino é estruturado de maneira bastante diferente do sistema britânico, diversas adaptações foram feitas. Os exemplos a seguir ilustram linhas de concordância em que é possível observar as principais adaptações observadas em relação aos termos relativos ao sistema de ensino no Brasil e no Reino Unido.

\begin{tabular}{|c|c|}
\hline $\begin{array}{l}\text { Tamsen } \\
\text { I AM NOT CATH! My name is Tamsen } \\
\text { Summers. I am in year ten at St } \\
\text { Nectans. I am beautiful and leggy and } \\
\text { witty and wonderful and that prick is } \\
\text { in love with me but he can't see it! }\end{array}$ & $\begin{array}{l}\text { Talita } \\
\text { Eu não sou a Carol! Meu nome é Talita } \\
\text { Amaral. Estudo no primeiro colegial do } \\
\text { Sagrado Coração. Eu sou linda, tenho cada } \\
\text { pernão, sou inteligente e maravilhosa e } \\
\text { aquele idiota está apaixonado por mim, só } \\
\text { que ele não consegue enxergar. }\end{array}$ \\
\hline $\begin{array}{l}\text { Stanley } \\
\text { My name's Stanley. I'm in Year Ten } \\
\text { in... }\end{array}$ & $\begin{array}{l}\text { Lucas } \\
\text { Meu nome é Lucas. Estou no primeiro } \\
\text { colegial... }\end{array}$ \\
\hline $\begin{array}{l}\text { Tamsen } \\
\text { This is Clive Marshall. He's in year Ten } \\
\text { and he sits next to Hugh Phillips and } \\
\text { behind Caroline Kendall because he } \\
\text { fancies her but she thinks he's a dork. }\end{array}$ & $\begin{array}{l}\text { Talita } \\
\text { Este é Cauê Monteiro. Está no primeiro } \\
\text { colegial. Senta-se ao lado de Hugo Svezia } \\
\text { e atrás da Renata Cury, porque ele gosta } \\
\text { dela, mas ela acha ele um bobo. }\end{array}$ \\
\hline $\begin{array}{l}\text { Maisy } \\
\text { (...) Two Riverdale boys were pinning a } \\
\text { St Nectans ninth year up against a } \\
\text { statue of Vulcan. (...). }\end{array}$ & $\begin{array}{l}\text { Gabi } \\
\text { (...) Dois brucutus do Rubinato estavam } \\
\text { empurrando um rapaz da oitava série do } \\
\text { Sagrado Coração contra a estátua de } \\
\text { Júpiter. (...). }\end{array}$ \\
\hline
\end{tabular}

Pela análise das linhas de concordância acima, observamos que year tem foi traduzido como "primeiro colegial", pelas razões já explicitadas anteriormente. E no exemplo a seguir observamos que ninth year foi substituído por seu equivalente "oitava série". 
Perrotti-Garcia, Ana J ulia - Análise da tradução/ adaptação de textos dramáticos sob a perspectiva da Linguística de Corpus

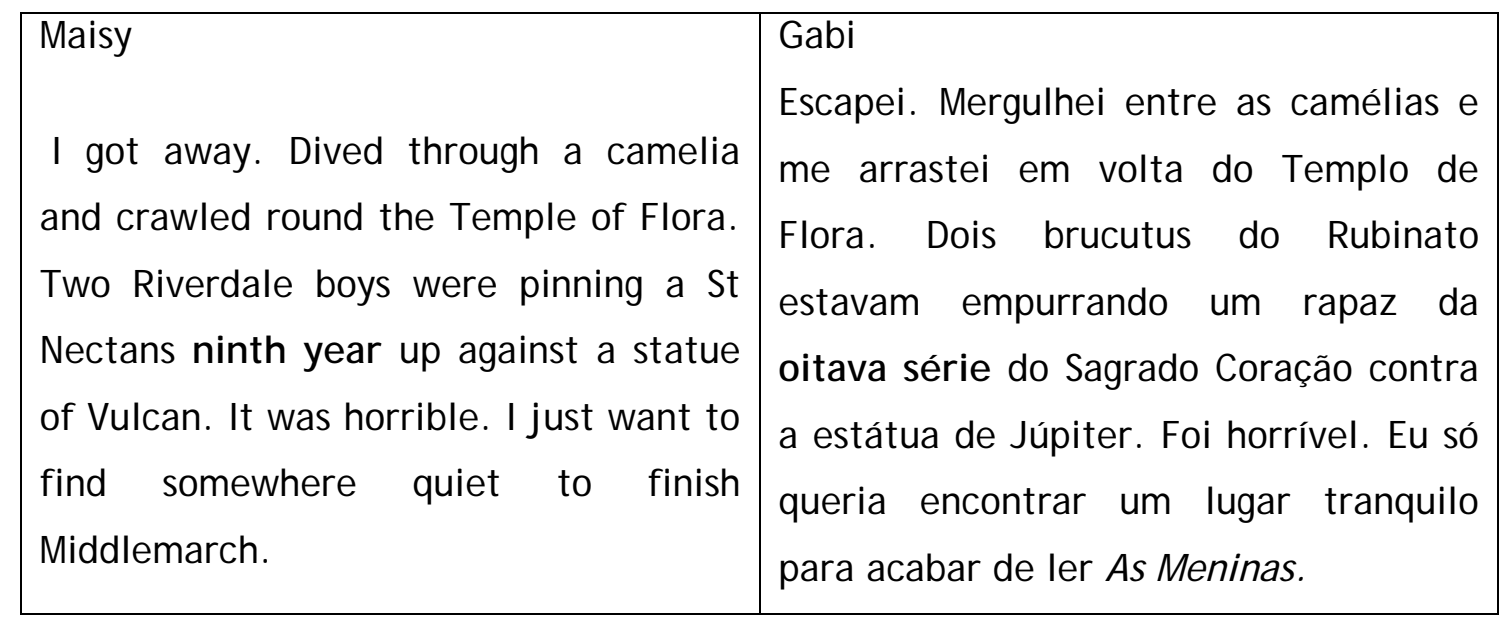

No Brasil, em geral, os uniformes não são compostos por Blazers, mas sim por camisetas, então, nos excertos a seguir, manter o termo original (purple blazers) poderia causar confusão (em geral, blazer é uma roupa vestida em ocasiões festivas) ou confundir quem assiste à peça. Assim, a versão em português mantém a referência à cor da roupa e troca blazers pelo termo mais neutro e genérico "uniforme".

\begin{tabular}{|l|l|}
\hline $\begin{array}{l}\text { Stanley } \\
\text { And why? Because they've got purple } \\
\text { blazers? Why Fraze? }\end{array}$ & $\begin{array}{l}\text { Lucas } \\
\text { Por que eles usam uniforme roxo? Por } \\
\text { que, Tiago? }\end{array}$ \\
\hline
\end{tabular}

Também por causa da maior formalidade presente no sistema educacional britânico, em que os professores são tratados pelo sobrenome, acrescidos do título Mr. ou Mrs., podemos observar algumas adaptações que se fizeram necessárias. A Sra. Gunnasekara foi substituída por "dona Ana Maria” e o professor "Geraldo" foi citado como professor de física, ao invés do Sr. Hemment presente no original.

\begin{tabular}{|c|c|}
\hline $\begin{array}{l}\text { Billie } \\
\text { He was being given his Creative } \\
\text { partnerships activity pack by Mrs } \\
\text { Gunnasekara. }\end{array}$ & $\begin{array}{l}\text { Bia } \\
\text { Foi bem na hora que } \\
\text { tava entregando o rot } \\
\text { Criativas para ele. }\end{array}$ \\
\hline $\begin{array}{l}\text { Billie } \\
\text { Frase I thin } \\
\text { Gunnasekk }\end{array}$ & \begin{tabular}{|l} 
Bia \\
Tiago, \\
dona A
\end{tabular} \\
\hline
\end{tabular}


Perrotti-Garcia, Ana J ulia - Análise da tradução/ adaptação de textos dramáticos sob a perspectiva da Linguística de Corpus

\begin{tabular}{|c|c|}
\hline $\begin{array}{l}\text { Tamsen } \\
\text { Clare Wyatt and Tara Willoughby. } \\
\text { What's the name of the physics } \\
\text { teacher? }\end{array}$ & $\begin{array}{l}\text { Talita } \\
\text { Clara Machado e Bebel Figueiredo. Como } \\
\text { se chama mesmo o seu professor de } \\
\text { Física? }\end{array}$ \\
\hline $\begin{array}{l}\text { Tamsen } \\
\text { Mr Hemment. Who won the victor } \\
\text { ludorum for the long jump at the } \\
\text { school sports day? }\end{array}$ & $\begin{array}{l}\text { Talita } \\
\text { Geraldo. Quem ganhou o troféu de salto a } \\
\text { distância nas olimpíadas escolares? }\end{array}$ \\
\hline
\end{tabular}

Algumas adaptações também foram necessárias para que o texto ficasse mais próximo da cultura de chegada, como é o caso de thirty words, que foi trocado por "vinte linhas", apresentado a seguir, que procura refletir 0 costume brasileiro de quantificar os textos e redações escolares por linhas, e não por palavras como ocorre nas escolas britânicas.

\begin{tabular}{|l|l|}
\hline Cath & Carol \\
"Describe in thirty words how visiting & $\begin{array}{l}\text { "Descreva em vinte linhas como a visita ao } \\
\text { the garden has changed your views on } \\
\text { jardim mudou sua visão da natureza e do } \\
\text { the nature of love". Like hello? }\end{array}$ \\
\hline
\end{tabular}

Nos dois excertos a seguir, observamos adaptações que se fizeram necessárias pela diferença entre os sistemas de ensino de ambos. Entretanto, no primeiro deles, temos uma alteração bastante grande no sentido do texto, e uma possível modificação na personagem, em consequência disso. Segundo o site A-levels, o Advanced Level, mais conhecido como A-level, é um curso com cerca de dois anos de duração oferecido por instituições educacionais britânicas e funciona como uma forma de qualificação. Os A-levels são, portanto, feitos por estudantes que pretendem continuar estudando, e que são dedicados ao estudo. Na adaptação, foi usado o termo "exames finais", que além de não ser um curso, é um tipo de prova em geral feito por alunos que não obtiveram notas mínimas para passarem sem tais exames. 0 mesmo ocorreu no segundo exemplo, em que GCSE (sigla do termo em inglês para o Certificado Geral de Educação Secundária) também foi traduzido por "exames", mais uma vez trocando testes que devem ser feitos por todos os alunos britânicos, por provas que apenas os alunos brasileiros com menor rendimento escolar precisam fazer. 
Perrotti-Garcia, Ana J ulia - Análise da tradução/ adaptação de textos dramáticos sob a perspectiva da Linguística de Corpus

\begin{tabular}{|l|l|}
\hline Cath & Carol \\
Yeah. And then I'll do five A levels. \\
$\begin{array}{l}\text { Maths, further maths, even further } \\
\text { maths, drama and Politics. }\end{array}$ & $\begin{array}{l}\text { Matemática, mais matemática, ainda mais } \\
\text { matemática, teatro e política. }\end{array}$ \\
\hline $\begin{array}{l}\text { Stanley } \\
\text { Wow! I want to take politics. Thing is I } \\
\text { reckon I'm going to fail all my GCSE's } \\
\text { which is a drawback. }\end{array}$ & $\begin{array}{l}\text { Lucas } \\
\text { Puxa! Eu queria estudar política. o } \\
\text { problema é que eu acho que vou bombar } \\
\text { todos os meus exames. Isso vai ser um } \\
\text { embaço. }\end{array}$ \\
\hline
\end{tabular}

\section{f. Trechos com adaptações mais extensas}

Em alguns pontos do texto, foram feitas adaptações mais profundas e detalhadas, como podemos observar no diálogo a seguir, em que, além dos nomes terem sido trocados, houve mudanças na nacionalidade de uma pessoa citada. No caso, como a conversa girava em torno de mulheres com busto grande, o que aparentemente parece ser a imagem que os britânicos têm das brasileiras e latinas, a tradução levou em consideração o estereótipo de mulher americana e trocou, muito habilmente, o termo Brazilian por "americana" e, a seguir, Costa Rican por "canadense":

\begin{tabular}{|l|l|}
\hline Cath & Carol \\
I wish I could change the way I looked. & Gostaria de poder mudar o meu visual. \\
Wipe it all out and start again. I'd go & Apagar tudo e começar do zero. Eu \\
online and buy Kelly Fisher's legs - & compraria pela Internet as pernas da \\
click buy Bryony Sturrock's arse - click & Rebeca Lima, a bunda da Camila Souza, \\
Sandra Estevez' tits. Proceed to & $\begin{array}{l}\text { os peitos da Sandra Estevez. Pronto! } \\
\text { checkout. }\end{array}$ \\
\hline $\begin{array}{l}\text { Billie } \\
\text { Sandra Estevez has got the best tits in } \\
\text { year ten. }\end{array}$ & $\begin{array}{l}\text { Bia } \\
\text { Sandra Estevez tem os melhores peitos da } \\
\text { Cath }\end{array}$ \\
Classe. \\
\hline Her dad's Brazilian. & Carol \\
Billie & A mãe dela é americana. \\
Costa Rican. & Bia \\
\hline
\end{tabular}


Perrotti-Garcia, Ana J ulia - Análise da tradução/ adaptação de textos dramáticos sob a perspectiva da Linguística de Corpus

O adaptador tem a liberdade de eliminar e/ ou acrescentar trechos à obra adaptada, quando isso se fizer necessário, como podemos observar 0 excerto a seguir. A personagem estava lendo um livro, cujo enredo seria importante para a trama da peça, e que, inclusive, alguns trechos seriam lidos em voz alta para outro personagem. Por essa razão, era importante que 0 livro fosse conhecido do público-alvo. Como a peça brasileira destinava-se basicamente a adolescentes, o texto em português utiliza Lygia Fagundes Telles, conhecida escritora nacional. Evidentemente, toda escolha pode ter perdas, e foi o que ocorreu aqui. No original, a escritora George Eliot tinha um nome masculino, o que gerou uma situação cômica. O personagem Rock, caracterizado por não gostar de ler, pensa que Eliot é homem, e Maisy diz It's a woman, silly. Lygia é um nome exclusivamente feminino, não teria como manter o mal entendido do original. Na adaptação, a personagem Gabi (Maisy), ao invés de chamar Geleia de bobo, por ele não saber que se trata de uma mulher, diz apenas "É uma mulher e tanto, bobo", como se ele fosse bobo por não conhecer alguém tão famoso. Uma solução bastante interessante. Além disso, ao trocar de escritora, também foi preciso trocar a obra citada (de Middlemarch para As Meninas), e modificar a fala toda, já que Maisy fazia um pequeno resumo da história.

\begin{tabular}{|l|l|}
\hline $\begin{array}{l}\text { Maisy } \\
\text { Middlemarch. It's a novel by George }\end{array}$ & $\begin{array}{l}\text { Gabi } \\
\text { As Meninas. É um romance da Lygia } \\
\text { Fagundes Telles. }\end{array}$ \\
\hline $\begin{array}{l}\text { Rock } \\
\text { Never heard of him. }\end{array}$ & $\begin{array}{l}\text { Geleia } \\
\text { Nunca ouvi falar. }\end{array}$ \\
\hline $\begin{array}{l}\text { Maisy } \\
\text { It's a woman, silly. She writes about a a } \\
\text { nineteenth century woman who is } \\
\text { trapped by her society into marrying } \\
\text { for respectability rather than for love. } \\
\text { George Eliot is my second favourite } \\
\text { author. }\end{array}$ & $\begin{array}{l}\text { Sabre três meninas que viviam em São } \\
\text { militar, que teve no Brasil em 1964. A } \\
\text { Lygia é a minha segunda escritora } \\
\text { preferida. }\end{array}$ \\
\hline
\end{tabular}

Na sequência do diálogo, ainda nesse mesmo trecho, a personagem passa a falar de mais uma escritora, cujo nome que também foi substituído na 
Perrotti-Garcia, Ana J ulia - Análise da tradução/ adaptação de textos dramáticos sob a perspectiva da Linguística de Corpus

obra traduzida. Jane Austen foi trocada por Cecília Meireles, assim como Emma por Romanceiro da Inconfidência. Nas linhas de concordância a seguir, podemos observar que duas falas foram totalmente suprimidas, assim como a afirmação que precedeu esse diálogo ("And my favorite character is $\mathbf{M r}$ Knightley").

\begin{tabular}{|c|c|}
\hline $\begin{array}{l}\text { Maisy } \\
\text { It's J ane Austen. My favorite book is Emma. } \\
\text { And my favorite character is Mr Knightley. }\end{array}$ & $\begin{array}{l}\text { Gabi } \\
\text { Cecília Meireles. Meu livro } \\
\text { preferido é Romanceiro da } \\
\text { Inconfidência. SUPRIMIDO }\end{array}$ \\
\hline $\begin{array}{l}\text { Rock } \\
\text { What's he like then? }\end{array}$ & SUPRIMIDO \\
\hline $\begin{array}{l}\text { Maisy } \\
\text { He's quiet, unassuming and in some ways } \\
\text { shy, but with an inner moral integrity that } \\
\text { Emma finally finds irresistible. }\end{array}$ & SUPRIMIDO \\
\hline $\begin{array}{l}\text { Maisy } \\
\text { It's good for hiding under camellias. Now I'm } \\
\text { already on chapter twenty seven so I need } \\
\text { to start by giving you a summary of the story } \\
\text { so far... Dorothea, a passionate young } \\
\text { woman in search of a belief system to } \\
\text { match the agitation of her mind, marries } \\
\text { the dark and skeletal figure of Mr } \\
\text { Casaubon... }\end{array}$ & $\begin{array}{l}\text { Gabi } \\
\text { É bom para se esconder debaixo das } \\
\text { camélias. Já estou no capítulo } 7, \\
\text { então preciso fazer um resumo do } \\
\text { começo. o livro é a história de } \\
\text { três meninas que ficam amigas. } \\
\text { Lorena, Ana Clara e Lia. Elas } \\
\text { vivem num pensionato, em pleno } \\
\text { regime militar. Cada uma tem uma } \\
\text { origem social e familiar... }\end{array}$ \\
\hline
\end{tabular}

Como podemos observar pela análise do texto alinhado apresentado anteriormente, ao trocar o título do livro, o adaptador também teve que modificar o número do capítulo, de 27 para 7, uma vez que o livro em português é menor, tendo apenas 12 capítulos. Já no trecho a seguir, continuação da conversa dos mesmos personagens, o capítulo 62 foi trocado por capítulo 9, pelas mesmas razões citadas anteriormente, e o trecho lido foi trocado por um excerto do capítulo 9 de As Meninas, mantendo o mesmo clima de romance e emoção expresso no original. 
Perrotti-Garcia, Ana J ulia - Análise da tradução/ adaptação de textos dramáticos sob a perspectiva da Linguística de Corpus

\begin{tabular}{|c|c|}
\hline $\begin{array}{l}\text { Maisy } \\
\text { If we don't stop kissing I won't be able } \\
\text { to get to the end of chapter sixty } \\
\text { two. And it's a corker. }\end{array}$ & $\begin{array}{l}\text { Gabi } \\
\text { Se não pararmos de nos beijar, nunca vou } \\
\text { chegar ao final do capítulo } \mathbf{9} \text {. Ele é } \\
\text { maravilhoso. }\end{array}$ \\
\hline $\begin{array}{l}\text { Rock } \\
\text { Sorry. Go on. }\end{array}$ & $\begin{array}{l}\text { Geléia } \\
\text { Desculpa. Continua. }\end{array}$ \\
\hline $\begin{array}{l}\text { Maisy } \\
\text { (begins to read) "She sank into the } \\
\text { chair and for a few moments sat } \\
\text { there like a statue, while images and } \\
\text { emotions were hurrying upon her. } \\
\text { J oy came first - joy in the impression } \\
\text { that it was really herself whom Will } \\
\text { loved..." }\end{array}$ & $\begin{array}{l}\text { Gabi } \\
\text { (começa a ler) Antes de desaparecer na } \\
\text { curva da alameda, se volta e me manda } \\
\text { beijos. Retribuo e sinto os olhos } \\
\text { úmidos, não sei se de emoção, não sei } \\
\text { por causa do sol desabrochado em raios } \\
\text { como na sua camisa..." }\end{array}$ \\
\hline
\end{tabular}

No diálogo entre Hugh e Cath, o personagem masculino cita o filme Pride and Prejudice e faz referência a Matthew Macfadyen, famoso entre 0 público jovem britânico por interpretar uma série televisiva chamada Spooks, produzida pela BBC, que contracena com Keira Knightley uma famosa cena de beijo. Embora Orgulho e Preconceito seja um livro relativamente conhecido no Brasil, o filme homônimo não chegou a despertar o interesse dos jovens brasileiros. Assim, a versão em português cita um filme bem mais famoso da cultura de chegada - Titanic - e, ao invés do nome da atriz, cita Leonardo de Caprio, que é um nome muito mais conhecido no Brasil, até por já ter sido namorado da top model brasileira Gisele Bündchen.

\begin{tabular}{|l|l|}
\hline Hugh & Hugo \\
Then she's more evil than I thought. & Então ela é mais abominável do que eu \\
(to cath) We went to see Pride and & pensava (para Carol) Nós assistimos Titanic \\
Prejudice! We kissed at the same & juntos! Três vezes! A gente se beijou na \\
time that the guy from Spooks & mesma hora que o Leonardo de Caprio dá \\
kissed Keira Knightley! I bought you & um cato naquela mina! \\
popcorn! & $\begin{array}{l}\text { Comprei pipoca para você. E Coca-Cola. } \\
\text { Grande! }\end{array}$ \\
\hline $\begin{array}{l}\text { Cath } \\
\text { I've never seen Pride and whatever } \\
\ldots\end{array}$ & Carol \\
\hline
\end{tabular}

Do mesmo modo que o adaptador tem liberdade para suprimir trechos que considere desnecessário, também tem autonomia para acrescentar pequenas alterações. No caso acima observamos que a exclamação "E Coca- 
Perrotti-Garcia, Ana J ulia - Análise da tradução/ adaptação de textos dramáticos sob a perspectiva da Linguística de Corpus

Cola. Grande!" não aparece no original. Esse acréscimo torna o texto mais próximo do costume dos jovens brasileiros urbanos, de comprar refrigerantes ao ir ao cinema. E reforça o clima de indignação do personagem, que havia comprado o refrigerante maior (e mais caro), e depois ter sido traído pela namorada.

Conforme já citamos anteriormente, embora gírias, palavras de baixo calão e expressões indicativas de oralidade tenham sido bastante frequentes e muito pudéssemos falar sobre sua tradução nesta pesquisa, esses temas ficarão reservados para estudos posteriores, havendo espaço para novas pesquisas.

\section{Conclusões}

A partir da pesquisa aqui realizada, pudemos concluir que as ferramentas computacionais ajudam na sistematização e no tratamento dos dados a serem analisados, tornando mais ágil e consistente a manipulação dos textos a serem pesquisados. Quanto mais longo for o texto dramático a ser estudado, maiores serão as contribuições do uso de ferramentas computacionais. Evidentemente, apesar dessa aparente automatização do processo, as análises propriamente ditas continuam a ser feitas manualmente, pela leitura atenta, pesquisa de contexto, reflexão e ponderação. As estratégias cognitivas não são substituídas pelos processos computadorizados. o computador apenas ajuda nas tarefas que seriam repetitivas ou muito trabalhosas (busca de termos, organização de ocorrências por frequência, classificação em ordem alfabética, entre outras). A tecnologia jamais irá substituir a sensibilidade e a capacidade de análise dos seres humanos, nem seu bom senso e livre arbítrio, as ferramentas computadorizadas podem ajudar a aumentar a consistência e a reduzir o tempo gasto no tratamento dos dados, e na organização e sistematização das ideais. 
Perrotti-Garcia, Ana J ulia - Análise da tradução/ adaptação de textos dramáticos sob a perspectiva da Linguística de Corpus

Concluímos que os recursos da Linguística de Corpus podem contribuir muito para as pesquisas em textos dramáticos traduzidos e adaptados, tanto em uma abordagem diacrônica, diatópica ou com outros parâmetros de pesquisa específicos desse tipo de textos.

\section{Referências bibliográficas}

BAKER, M. Corpora in Translation Studies: An Overview and Some Suggestions for Future Research. In: Target, v. 7, n. 2, 1995: 223-243.

BERBER SARDINHA, T. Usando WordSmith Tools na investigação da linguagem. In: DIRECT Papers, São Paulo, V. 40, 1999. Disponível em: বttp:// 74.125.47.132/ search?q=cache: w4Mel1s5HrY] : www2. lael. puc $\mathrm{sp} . \mathrm{br} /$ direct/ DirectPapers40. pdf +sardinha+type +token $+\mathrm{n} \%$ C3\%BAmero $\& c d=5 \& h l=p t-B R \& c t=c \mid n k \& g l=b r>.(20 / 09 / 2008)$. , T. Lingüística de corpus. Barueri: Editora Manole, 2004.

DANIELSSON, P. e RIDINGS, D. Practical Presentation of a "Vanilla" aligner. In Reyle, U. and Rohrer, C. (eds.). Apresentado em TELRI Workshop on Alignment and Exploitation of Texts. Institute Jozef Stefan. Ljubljana, 1997.

FonseCA, L. C. A tradução de binômios nos contratos de 'common law' à luz da lingüística de corpus. 2007. 403p. Dissertação (Mestrado em Estudos Linguísticos e Literários em Inglês) - $\quad$ Faculdade de Filosofia, Letras e Ciências Humanas (FFLCH) da Universidade de São Paulo, São Paulo, 2007.

FROMM, G. VoTec: a construção de vocabulários eletrônicos para aprendizes de tradução . 2008. 215p. Tese (Doutorado em Estudos Linguísticos e Literários em Inglês) - Faculdade de Filosofia, Letras e Ciências Humanas (FFLCH) da Universidade de São Paulo, São Paulo, 2008.

GINEZI, L. L. Cafés do Brasil: estudo de variantes em português e inglês na língua falada. 2008. 270p. Dissertação (Mestrado em Estudos Linguísticos e Literários em Inglês) - Faculdade de Filosofia, Letras e Ciências Humanas (FFLCH) da Universidade de São Paulo, São Paulo, 2008.

GonçALveS, L. B. 'Dubliners' sob a lupa da lingüística de corpus: uma contribuição para a análise e a avaliação da tradução literária. 2006. 327p. Tese (Doutorado em Estudos Linguísticos e Literários em Inglês) 
Perrotti-Garcia, Ana J ulia - Análise da tradução/ adaptação de textos dramáticos sob a perspectiva da Linguística de Corpus

- Faculdade de Filosofia, Letras e Ciências Humanas (FFLCH) da Universidade de São Paulo, São Paulo, 2007.

Lamparelli, A. H. de C. A. A naturalidade na tradução: quem garante? 2007. 250p. Dissertação (Mestrado em Estudos Linguísticos e Literários em Inglês) - Faculdade de Filosofia, Letras e Ciências Humanas (FFLCH) da Universidade de São Paulo, São Paulo, 2007.

LAVIOSA, S. Corpus-based translation studies: theory, findings, applications. Amsterdam: Editions Rodopi, 2002.

MaRTins, J. C. A terminologia do ecoturismo como espelho de diferentes visões: agências de turismo, ambientalistas e governo. 2007. 180p. Dissertação (Mestrado em Estudos Linguísticos e Literários em Inglês) - Faculdade de Filosofia, Letras e Ciências Humanas (FFLCH) da Universidade de São Paulo, São Paulo, 2008.

Partington, A. Aims, Tools and Practices of Corpus Linguistics. IntUne. University of Bologna, Bologna, jan. 2006. Disponível em: $\varangle w w w$. intune.it/ file_download/ 23>. (10/07/ 2008).

TEIXEIRA, E. D. A lingüística de corpus a serviço do tradutor: proposta de um dicionário de culinária voltado para a produção textual. 2008. 403p. Tese (Doutorado em Estudos Linguísticos e Literários em Inglês) - Faculdade de Filosofia, Letras e Ciências Humanas (FFLCH) da Universidade de São Paulo, São Paulo, 2009.

Telles, L. F. As Meninas. 5a. Ed. J osê Olympio: Rio de J aneiro, 1975.

\section{Sites citados}

A-LEveLS. Disponível em ঝhttp:// www.a-levels.co.uk/ >. (17/ 12/ 2010).

Biblioteca Digital de Teses e Dissertações da Universidade de São Paulo. Disponível em «ttp:// www. teses. usp. br/ >. (22/ 06/ 2010).

CEPRIL (PUC-SP) Corpus Analysis Toolkit (Mirror site). Disponível em «ttp:// corpuslg. org/ tools/ >. (27/ 12/ 2010).

DICIONÁRIO INFORMAL. Disponível em: বhttp:// www. dicionarioinformal. com. br/ buscar. php?palavra=brucutu>. (28 dez 2010).

FILOLOGIA.ORG.BR. Disponível em বhttp://www. filologia. org. br/anais/anais\%. (11/ 12/ 2010).

FUnDAÇÃo CASA. Disponível em: বhttp:// www. febem.sp.gov. br/ site/ paginas. php?sess $=6>$. $(20 / 12 / 2010)$. 
Perrotti-Garcia, Ana J ulia - Análise da tradução/ adaptação de textos dramáticos sob a perspectiva da Linguística de Corpus

Projeto Conexões. Disponível em: \http:// www.conexoes.org.br/ quadro01. php?id=00076\&canal $=$ SOBRE\&secao $=H \mid S T \%$ DRICO $>$. (10/01/2011).

WORDFAST. Disponível em <www. wordfast. net>. (16/ 04/ 2011). 